\title{
Damage pattern and damage progression on breakwater roundheads under multidirectional waves
}

\author{
F. Comola a,c,*, T. Lykke Andersen ${ }^{\text {b }}$, L. Martinelli ${ }^{a}$, H.F. Burcharth ${ }^{\text {b }}$, P. Ruol ${ }^{\text {a }}$ \\ ${ }^{a}$ Dept. of Civil, Environmental and Architectural Engineering, Università di Padova, Italy \\ b Dept. of Civil Engineering, Aalborg University, Denmark \\ ' CRYOS, School of Architecture, Civil and Environmental Engineering, École Polytechnique Fédérale de Lausanne, Switzerland
}

\section{A R T I C L E I N F O}

\section{Article history:}

Received 19 November 2012

Received in revised form 25 June 2013

Accepted 18 September 2013

Available online 17 October 2013

\section{Keywords:}

Damage pattern

Physical model

Rubble mound breakwater

Breakwater roundhead

Stability number

\begin{abstract}
A B S T R A C T
An experimental model test study is carried out to investigate damage pattern and progression on a rock armoured breakwater roundhead subjected to multidirectional waves. Concerning damage pattern, the most critical sector is observed to shift leeward with increasing wave period. Taking angles relative to mean wave direction, the critical sector is observed in the sector $10^{\circ}-55^{\circ}$ for short waves and in the sector $100^{\circ}-145^{\circ}$ for long waves. A probabilistic approach is developed to predict for one typical roundhead geometry the damage distribution depending on the incoming waves and structural characteristics. The damage progression is observed dependent on significant wave height and peak wave period, but not on the directional spreading and the spectral width of the incident waves. Combining the results of both damage pattern and damage progression, a stability formula for the distribution of damage over the roundhead is developed. Thus the formula also considers the shifting of the critical sector due to increasing wave period which existing formulae do not include. Finally, analysing the damage produced by double peaked spectra, it is shown that the armour may be designed by the formula when using the total significant wave height and an equivalent peak period.
\end{abstract}

(c) 2013 Elsevier B.V. All rights reserved

\section{Introduction}

The roundhead is a critical section of a rubble-mound breakwater in terms of armour unit stability. In fact the roundhead requires armour units that are significantly larger than on the trunk. This is due to an energy concentration at the roundhead caused by the combination of refraction, diffraction and shoaling but mainly due to the lack of support from neighbour armour units, and the large overflow velocities. Moreover, the stones are less interlocked and, if displaced, they are moved towards the rear side, failing to provide any residual stability to the section.

Over the last decades, many experimental studies have provided a deeper knowledge on roundhead stability, investigating the effect of the main hydraulic and structural parameters. Vidal et al. (1989, 1991), carrying out experiments using concrete cubes, observed that wave steepness has no effect on the occurrence of the start of damage, but has a noteworthy influence on damage progression. The same influence was observed by Madrigal and Lozano (1992) and by Berenguer and Baonza (1999). Carver and Heimbaugh (1989) observed that, for rock and dolos units, the minimum of stability occurs for a specific value of Iribarren number. The results obtained by Matsumi et al. (1996) evidenced that the spatial correlation of velocity

\footnotetext{
* Corresponding author at: EPFL ENAC IIE CRYOS, GR B0 421, Station 2, CH-1015
} Lausanne. magnitudes around the roundhead is much stronger under long waves than under short waves. Burcharth et al. (2003) identified a suitable parameter, given by a combination of $H_{s}, T_{m}$ and $D_{n}$, to characterize the threshold for damage initiation. A large number of authors, e.g. Jensen (1984), Vidal et al. (1991), Madrigal and Lozano (1992), Berenguer and Baonza (1999), Matsumi et al. (2000), and Burcharth et al. (2003), identified the effect of incident wave angle by observing that the most critical part of the roundhead is always in a sector between $90^{\circ}$ and $150^{\circ}$ from the wave mean direction. Maciñeira and Burcharth (2008) also observed for a cube armoured roundhead the critical sector to be from 90 to $135^{\circ}$ in most of the tests. However, they observed the same damage in the sectors $45-90^{\circ}$ and $90-135^{\circ}$ for waves with peak wave steepness above 0.04 . For head radius less than $12 \mathrm{D}_{\mathrm{n}}$ the difference in damage between sectors also was reduced. Systematic investigations performed by Matsumi et al. (1994, 1996, 1998, 2000) evidenced that the load applied to armour units increased with the directional spreading of the waves. No significant differences in roundhead stability between different types of armour units can be seen for roundhead stability in the investigations by Madrigal and Lozano (1992), who compared Accropodes and parallelepipedic blocks, and Berenguer and Baonza (1999), who compared antifer blocks and hollowed cubes. Jensen (1984), instead, found that interlocked units are more stable than massive units of the same mass but suggested, like Burcharth and Thompson (1983) and Burcharth et al. (2003), that increasing mass density is a much more efficient way to improve stability. Finally, the effect of roundhead radius at sea water level $R$ 


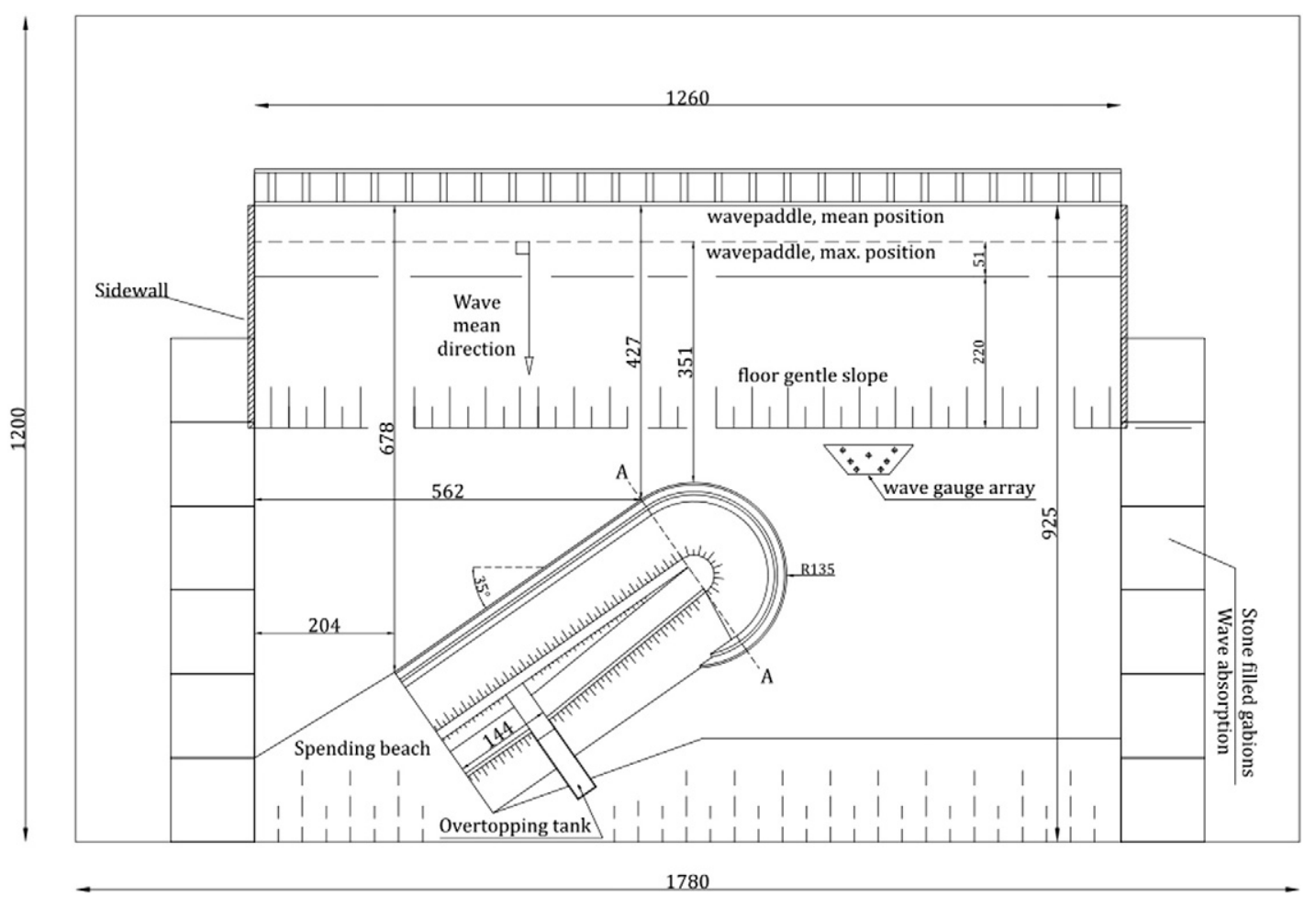

Fig. 1. Layout of the roundhead model (measures in centimetres).

has been investigated by Jensen (1984), who observed that stability increases if the radius increases. Moreover, Vidal et al. (1989) and Losada et al. (1990) suggested that the dimensionless ratio $R / L$ between radius and wave length is a suitable parameter to investigate the effect of diffraction and refraction on roundhead stability. The influence of radius was further studied by Maciñeira and Burcharth (2007) who concluded that the residual stability between start of damage and failure decreases with decrease in radius, but the effect was not found to be linear with the radius. In case of long period waves, they found a larger radius to have higher residual stability (7\% in case of 1:2 slope and $14 \%$ in case of 1:1.5 slope), while in case of short-period waves and steeper slopes, the behaviour was found to be opposite.

Many systematic investigations were also carried out to develop stability formulae, i.e. equations used to design the minimum mass of armour units required for stability. In general, the stability formulae developed for trunk sections may not be applied for roundheads, unless some of the parameters are modified to take into account the major brittleness of the roundhead compared to the trunk. For instance, the
Hudson formula (United States Army Corps of Engineers, 1984) provides lower $K_{D}$ values for roundhead than for trunk section. There exist also stability formulae specifically developed for roundheads, that eventually consider the damage level $D$ among the variables defining the mass of armour units. By using this type of formulae, the designer can decide the acceptable damage level that is supposed to take place under the design sea state conditions. However, being the damage level $D$ not homogeneous along the roundhead, most of the stability formulae proposed in literature (Berenguer and Baonza, 1999; Maciñeira and Burcharth, 2007) just consider the damage level in the critical sector, i.e. to the most damaged sector.

The formula of Berenguer and Baonza (1999) (Eq. (1)) was developed by analysing roundheads armoured with cubes and BCRs (antifer cubes), with slope angle 1:2, under unidirectional waves. The formula of Maciñeira and Burcharth (2007) (Eq. (2)), instead, was developed considering cube armoured roundheads having slope angles 1:1.5 and $1: 2$, both under unidirectional and directional waves. Moreover, Berenguer and Baonza divided the roundhead in three sectors

\section{Section A-A}

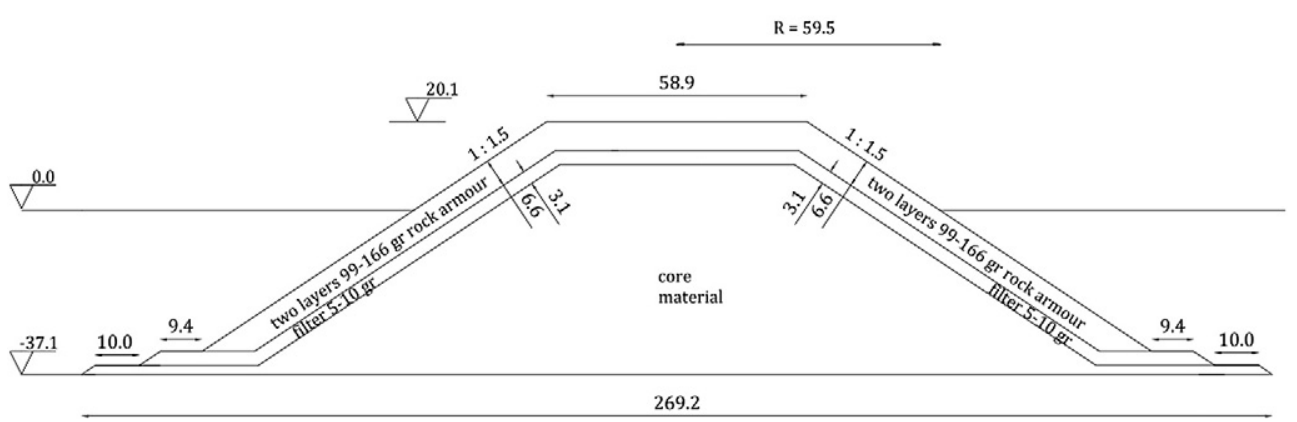

Fig. 2. Roundhead section (measures in centimetres). 
Table 1

Properties of the main armour stones in the model.

\begin{tabular}{lllc}
\hline & $\rho_{\mathrm{s}}\left[\mathrm{kg} / \mathrm{m}^{3}\right]$ & $D_{\mathrm{n} 50}[\mathrm{~cm}]$ & $M_{50}[\mathrm{~g}]$ \\
\hline Trunk armour & 2590 & 3.2 & 83 \\
Roundhead armour & 2650 & 3.6 & 128 \\
& & & \\
\hline & $\rho_{s}\left[\mathrm{~kg} / \mathrm{m}^{3}\right]$ & $D_{n}[\mathrm{~cm}]$ & $M[\mathrm{~g}]$ \\
\hline Trunk filter & 2680 & $1.04-1.31$ & $3-6$ \\
Roundhead filter & 2680 & $1.22-1.54$ & $5-10$ \\
\hline
\end{tabular}

Table 2

Range of $H_{s}$ in each test series and target wave parameters $T_{p}, \gamma$, and $s$.

\begin{tabular}{lllcc}
\hline & $H_{s}[\mathrm{~cm}]$ & $T_{p}[\mathrm{~s}]$ & $\gamma[-]$ & $s[-]$ \\
\hline Series A & $6.6-11.6$ & 1.4 & 3.3 & 50 \\
Series B & $6.6-10.6$ & 2.4 & 3.3 & 50 \\
Series C & $6.6-9.6$ & 3.4 & 3.3 & 50 \\
Series D & $6.6-11.6$ & 1.4 & 3.3 & 15 \\
Series E & $6.6-10.6$ & 2.4 & 3.3 & 15 \\
Series F & $6.6-9.6$ & 3.4 & 3.3 & 15 \\
Series G & $6.6-10.6$ & 1.4 & 3.3 & 5 \\
Series H & $6.6-9.6$ & 2.4 & 3.3 & 5 \\
Series I & $6.6-9.6$ & 3.4 & 3.3 & 5 \\
Series L & $6.6-9.6$ & 3.4 & 10 & 50 \\
Series M & $6.6-10.6$ & 2.4 & 10 & 15 \\
Series N & $6.6-11.6$ & 1.4 & 10 & 5 \\
\hline
\end{tabular}

$\left(0^{\circ}-30^{\circ} ; 30^{\circ}-90^{\circ} ; 90^{\circ}-150^{\circ}\right)$, while Maciñeira and Burcharth divided the roundhead in four sectors $\left(0^{\circ}-45^{\circ} ; 45^{\circ}-90^{\circ} ; 90^{\circ}-135^{\circ} ; 135^{\circ}-180^{\circ}\right)$.

$N_{s}=\frac{H_{s}}{\Delta D_{n 50}}=1.8+2.3 \cdot D_{c r i t}^{0.4} \cdot S_{0 m}^{0.5}$

$N_{s}=\frac{H_{s}}{\Delta D_{n 50}}=0.57 \cdot \exp \left(0.07 \cdot R_{n}\right) \cdot \cot ^{0.71} \alpha \cdot D_{\%, \text { crit }}^{0.2} \cdot S_{0 p}^{0.4}+2.08 \cdot S_{0 p}^{0.14}-0.17$

where:

$N_{s} \quad$ stability number;

$H_{s} \quad$ significant wave height;

$\Delta=\rho_{r} / \rho_{w}-1$ reduced relative density;

$D_{n 50}=\left(M_{50} / \rho_{r}\right)^{1 / 3} \quad$ equivalent cube length exceeded by $50 \%$ of the units;

$\rho_{r} \quad$ units mass density;

$\rho_{w} \quad$ water mass density;

$M_{50} \quad$ mass exceeded by $50 \%$ of the armour units;

$D_{\text {crit }} \in[0,1] \quad$ damage level in the critical sector, identified by Berenguer and Baonza as the one between $90^{\circ}$ and $150^{\circ}$ from wave mean direction;
$D_{\%, \text { crit }} \in[0,100]$ damage level in the critical sector, identified by Maciñeira and Burcharth as the one between $90^{\circ}$ and $150^{\circ}$ from wave mean direction;

$S_{0 p}=H_{s} / L_{0 p}=2 \pi H_{s} / g T_{p}{ }^{2}$ peak wave steepness using deep water peak wave length;

$S_{0 m}=H_{s} / L_{0 m}=2 \pi H_{s} / g T_{m}{ }^{2}$ mean wave steepness using deep water mean wave length;

$R_{n}=R / D_{n 50}$ dimensionless roundhead radius at SWL;

$\alpha \quad$ armour slope angle.

The great majority of the systematic investigations described in literature focused on the damage in the critical sector, without providing any information on the damage distribution over the roundhead. It is believed that further investigations on damage pattern and progression within all the sectors of the roundhead may be useful in predicting the number and the position of amour units that might be displaced under intensive wave attacks, as well as predicting the maintenance costs sustained for replacing these units. Furthermore, this information may be useful to decide whether it may be feasible to use units with different weight in the various sectors.

The purpose of this paper is therefore to provide additional information on damage pattern and progression on a breakwater roundhead, depending on the characteristics of the multidirectional incident waves. In order to carry out the experimental analysis, a breakwater physical model was set up in the shallow water basin at Aalborg University, Denmark. The tests were restricted to one head radius and one armour slope angle.

Sections 2 and 3 provide a description of the experimental facility and of the test programme. The results and analyses are discussed in Section 4. Finally, Section 5 provides guidelines for applications to double peaked spectra.

\section{Model test setup and experimental facility}

\subsection{Model layout in basin}

The basin used to perform the experimental testing is equipped with multi segmented snake type generator with 25 independent vertical hinged piston paddles $0.5 \mathrm{~m}$ wide, able to generate a 3D wave field in accordance with a specified spectrum. The basin, whose dimensions are $17.2 \times 12.0 \mathrm{~m}$, has partially absorbing gabions along the lateral boundaries and a spending beach along the boundary opposite to the generator. Next to the wave paddles, two reflecting barriers are placed in order to improve the capability of generating oblique waves.

The orientation of the model in the basin is shown in Fig. 1. The angle of incidence between the mean direction of the waves (normal to the paddle) and the normal to the trunk is $35^{\circ}$ (see Fig. 3 ). This angle is very large and quite unusual if compared to the angles
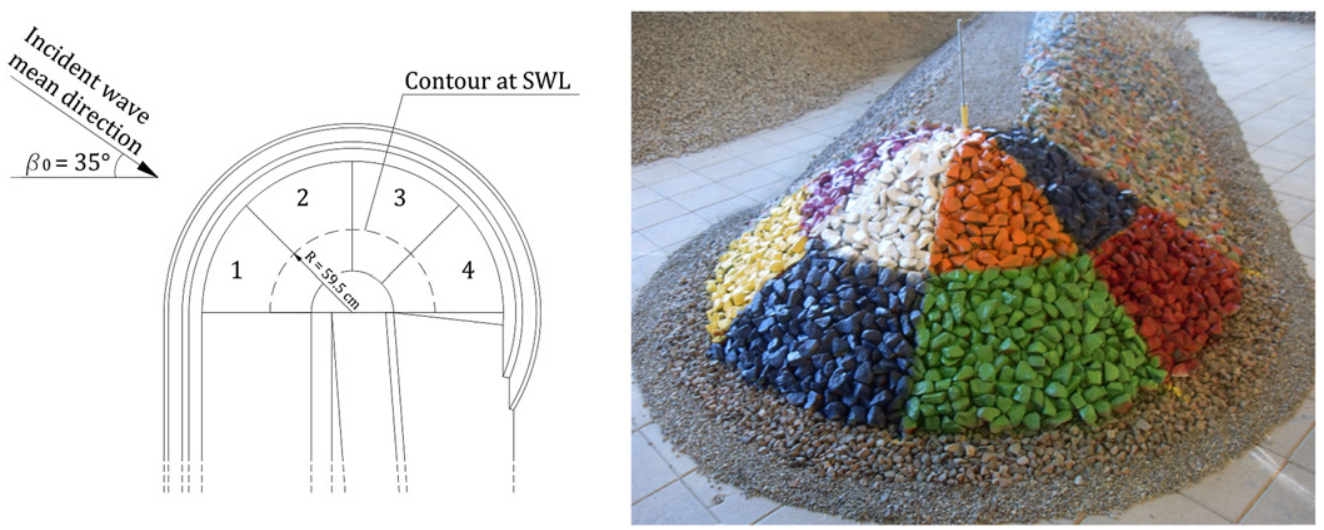

Fig. 3. Representation of the roundhead sectors and picture of the model. 


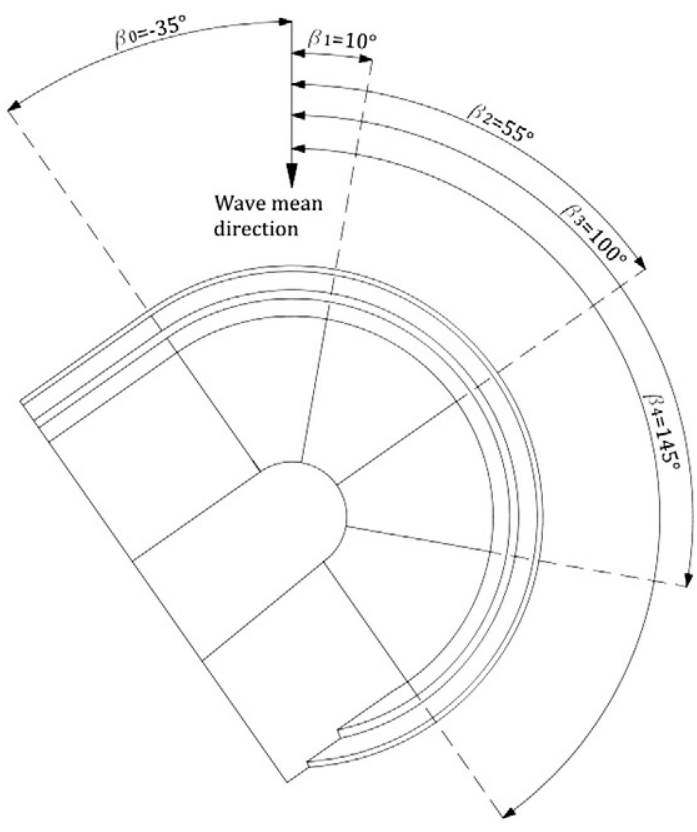

Fig. 4. Delimiting angles of each sector with respect to the mean wave direction.

used in other experimental investigations described in literature (e.g. Maciñeira and Burcharth, 2007, carried out their tests in the same basin turning the model $5^{\circ}$ with respect to the wave mean direction). However, an angle of incidence of $35^{\circ}$ is representative of many operating conditions.

An array of 7 resistance type wave gauges is placed next to the roundhead to provide directional information on the incident waves using BDM method (Hashimoto, 1988).

Fig. 2 shows a section of the roundhead. During the experimental tests the water depth at the model is set equal to $37.1 \mathrm{~cm}$, producing a radius $R$ at SWL equal to $59.5 \mathrm{~cm}$.

\subsection{Model stone units}

Table 1 presents the stone properties used to build the roundhead armour and filter layers.

The mass density for the armour stones in the model is measured considering the mean value of a consistent number of units. Moreover, the weight of each single stone used for the armour layer is measured before the set-up: only stones whose weight fit a reasonable range around $M_{50}$ are considered acceptable ( $\pm 25 \%$ with respect to $M_{50}$ as suggested by SPM (1984)).

The stones are placed randomly in double layer adopting a packing density of 910 units $/ \mathrm{m}^{2}$ and an armour porosity of $29 \%$. The roundhead armour contains 1800 stones.

The viscous force scale effects related to armour stability are assumed to be negligible as long as the Reynolds number exceeds the critical value proposed by Dai and Kamel (1969), i.e. $R e=$ $U \cdot D_{n 50} / \nu>3 \cdot 10^{4}$. This condition is respected for the performed tests, in which the Reynolds number is approximately $4 \cdot 10^{4}$. Clearly, other processes such as run-up, overtopping, bed erosion and toe scour may be affected by scale affects also for larger Reynolds numbers (De Rouck et al., 2005; Lykke Andersen et al., 2010; Martinelli et al., 2006).

\section{Test procedure}

Twelve test series with multidirectional waves are carried out, each one characterized by JONSWAP spectrum with a wave peak period $T_{p}$, peak enhancement factor $\gamma$ and directional spreading $s$. During each series a certain number of tests with increase of $H_{s}$ is carried out, until the filter layer appears exposed for an area wider than $D_{n 50} . H_{s}$ is increased by approximately $10 \%$ from test to test. Overall, a total number of 70 experimental tests are carried out. In each test 1000 waves are reproduced.

Being $T_{p}$ fixed and $H_{s}$ variable during each series, the wave steepness $S_{0 p}$ changes within the same series. This approach is therefore different from the one adopted in Maciñeira and Burcharth (2007) and Maciñeira (2004), where $S_{0 p}$ was fixed.

The range of $H_{\mathrm{s}}$ in each test series and the target parameters $T_{p}, \gamma$, and $s$ are reported in Table 2, where $s$ is the directional spreading parameter in the Longuet-Higgins spreading function given below.

$D(f, \theta)=\frac{2^{2 s-1}}{\pi} \frac{\Gamma^{2}(s+1)}{\Gamma(2 s+1)} \cos ^{2 s}\left(\frac{\theta-\theta_{0}}{2}\right)$.

The test programme involving double peaked spectra is presented in Section 5.

The head is divided in four $45^{\circ}$ sectors as shown in Fig. 3. In order to easily identify the stone displacements, the areas above and below SWL are visually separated by painting the stones with different colours.

Each sector $i$ is delimited by two angles $\beta_{i-1}$ and $\beta_{i}\left(\beta_{0}=-35^{\circ}\right.$, $\beta_{1}=10^{\circ}, \beta_{2}=55^{\circ}, \beta_{3}=100^{\circ}, \beta_{4}=145^{\circ}$ ), defined from the mean direction of the incident waves and conventionally positive if clockwise, as shown in Fig. 4. The profile of the armour layer is rebuilt at the end of each test series.

The evaluation of the damage is done considering the number of units displaced for a distance larger than $D_{n 50}$ in the active zone, which can be expressed as the area between the levels $\mathrm{SWL} \pm n D_{n 50}$ as suggested by Burcharth and Hughes (2002). During the execution of the tests, it was observed that $n=3$ properly identifies the active zone of the roundhead. The number of displaced units is identified by overlay of digital photos taken before and after each test.

\section{Results and analysis}

This section provides the analysis of damage pattern and progression within the roundhead. All test results can be found in Comola (2012).

\subsection{Damage pattern}

The following analysis suggests which sectors are effectively the most subjected to stone displacements, depending on the incident wave characteristics. One must specify that, for the tested experimental conditions, displacements of the leeward stones are never induced by overtopping. It is observed that the frontal sectors ( 1 and 2 ) are clearly more damaged under shorter wave periods, while the rear sectors ( 3 and 4) are more damaged under longer ones. Moreover, it seems that under shorter wave periods the damage distribution is more uniform than under longer periods.

\section{Table 3}

Observed damage pattern in terms of fraction of displaced units in each sector ?P

\begin{tabular}{llrrrrrrl}
\hline Series & $T_{p}[\mathrm{~s}]$ & $\mathrm{s}[-]$ & $\gamma[-]$ & $R / L_{0 p}$ & \multicolumn{1}{c}{$\Delta P_{1}[\%]$} & $\Delta P_{2}[\%]$ & \multicolumn{1}{c}{$\Delta P_{3}[\%]$} & $\Delta P_{4}[\%]$ \\
\hline A & 1.4 & 50 & 3.3 & 0.21 & 20.2 & 39.4 & 23.2 & 17.2 \\
B & 2.4 & 50 & 3.3 & 0.07 & 8.5 & 25.6 & 37.2 & 28.7 \\
C & 3.4 & 50 & 3.3 & 0.03 & 3.1 & 0.0 & 33.8 & 63.1 \\
D & 1.4 & 15 & 3.3 & 0.21 & 30.8 & 47.4 & 9.0 & 12.8 \\
E & 2.4 & 15 & 3.3 & 0.07 & 11.0 & 7.3 & 29.4 & 52.3 \\
F & 3.4 & 15 & 3.3 & 0.03 & 1.4 & 2.9 & 41.4 & 54.3 \\
G & 1.4 & 5 & 3.3 & 0.21 & 40.4 & 38.6 & 5.3 & 15.8 \\
H & 2.4 & 5 & 3.3 & 0.07 & 3.9 & 3.9 & 28.2 & 64.1 \\
I & 3.4 & 5 & 3.3 & 0.03 & 2.8 & 0.0 & 4.7 & 92.5 \\
L & 3.4 & 50 & 10.0 & 0.03 & 1.4 & 1.4 & 32.4 & 64.8 \\
M & 2.4 & 15 & 10.0 & 0.07 & 13.3 & 1.9 & 22.9 & 61.9 \\
N & 1.4 & 5 & 10.0 & 0.21 & 5.8 & 59.3 & 11.6 & 23.3 \\
\hline
\end{tabular}




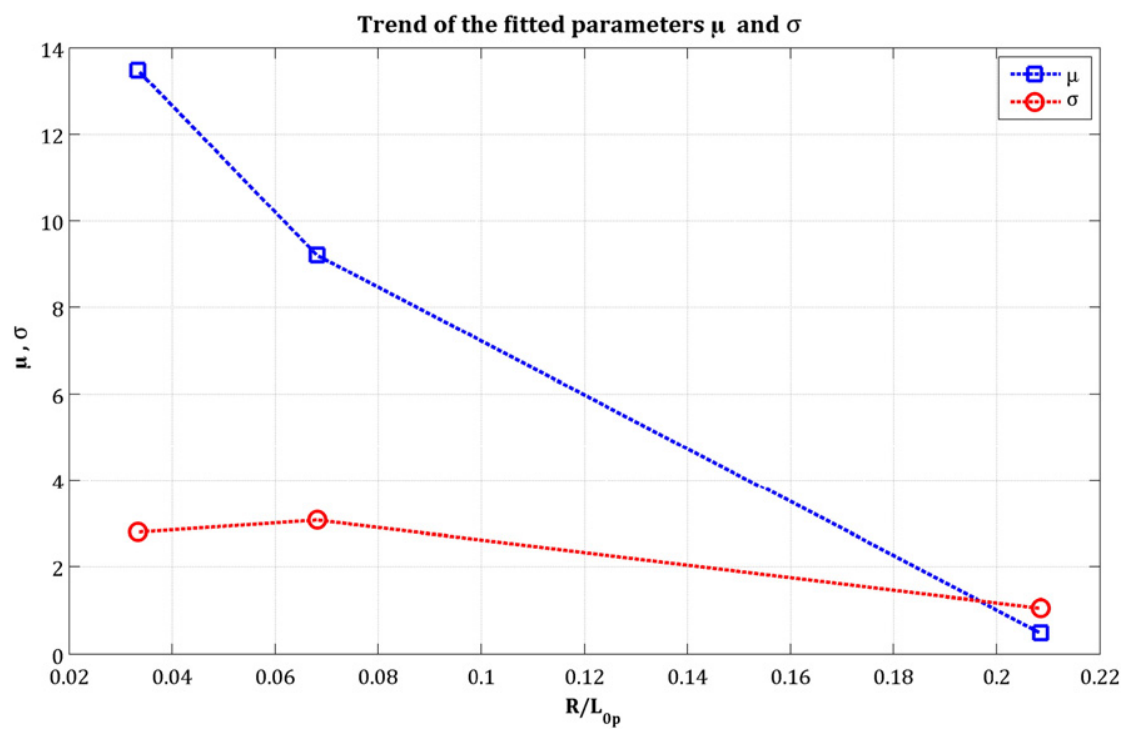

Fig. 5. Values of the fitted parameters $\mu$ and $\sigma$ for each value of tested ratio $R / L_{0 p}$.

A damage pattern analysis is performed to characterize these observations by means of a probability density function $p(\beta)$, describing the probability that each stone displacement takes place in a position identified by the angle $\beta \in\left[\beta_{0} ; \pi+\beta_{0}\right]$. The proposed $p d f$, given in Eq. (4), is the Truncated Normal Distribution, defined in a bounded interval $\left[\beta_{0} ; \pi+\beta_{0}\right]$

$p(\beta)=\frac{f\left(\beta ; \mu, \sigma^{2}\right)}{F\left(\pi+\beta_{0} ; \mu, \sigma^{2}\right)-F\left(\beta_{0} ; \mu, \sigma^{2}\right)}$

where $f$ is the normal probability density function, $F$ is the cumulative distribution function of $f$ and $\beta_{0}, \mu$, and $\sigma^{2}$ are parameters of this distribution. Note that $\mu$ and $\sigma^{2}$ are related to the Gaussian distribution and do not coincide with the mean and variance of the $p(\beta)$, but the analytical relationship between them can be found for example in Johnson et al. (1994). The observed damage pattern is given in Table 3 in terms of the fraction $\Delta P$ of displaced units occurring in each sector.

In Table 3, each series is associated to a specific value of the $R / L_{0 p}$ ratio. $R$ is the roundhead radius at SWL defined in Fig. 2, that is not modified during the tests and is used as scaling variable. $L_{0 p}$ is the offshore wave length associated to the peak period. $R / L_{0 p}$ therefore represents a diffraction non-dimensional parameter, as was also proposed by Vidal et al. (1989) and Losada et al. (1990).

In total three values of $R / L_{0 p}$ are tested $(0.03,0.07,0.21)$. The distribution of Eq. (4) is fitted to each of the three identified set of tests, providing the $\sigma$ and $\mu$ values shown in Fig. 5. The three resulting $p d f$ give the fitted damage distribution over the head and are plotted in Fig. 6, whereas Figs. 7, 8 and 9 show the cumulative distribution functions ( $c d f)$ together with the data.

It may be observed that $p(\beta)$ in Fig. 6 changes as a function on $R / L_{0 p}$ in a way that is consistent to what has been preliminary observed for the damage pattern. In fact, under short wave attack $\left(R / L_{0 p}=0.21\right)$ the frontal sectors are more prone to be damaged than the rear ones, and vice versa.

In conclusion, the results of the damage pattern analysis have pointed out the following important trends:

- the tests did not confirm what was observed in previous investigations, i.e. that the critical sector is uniquely determined by the incident

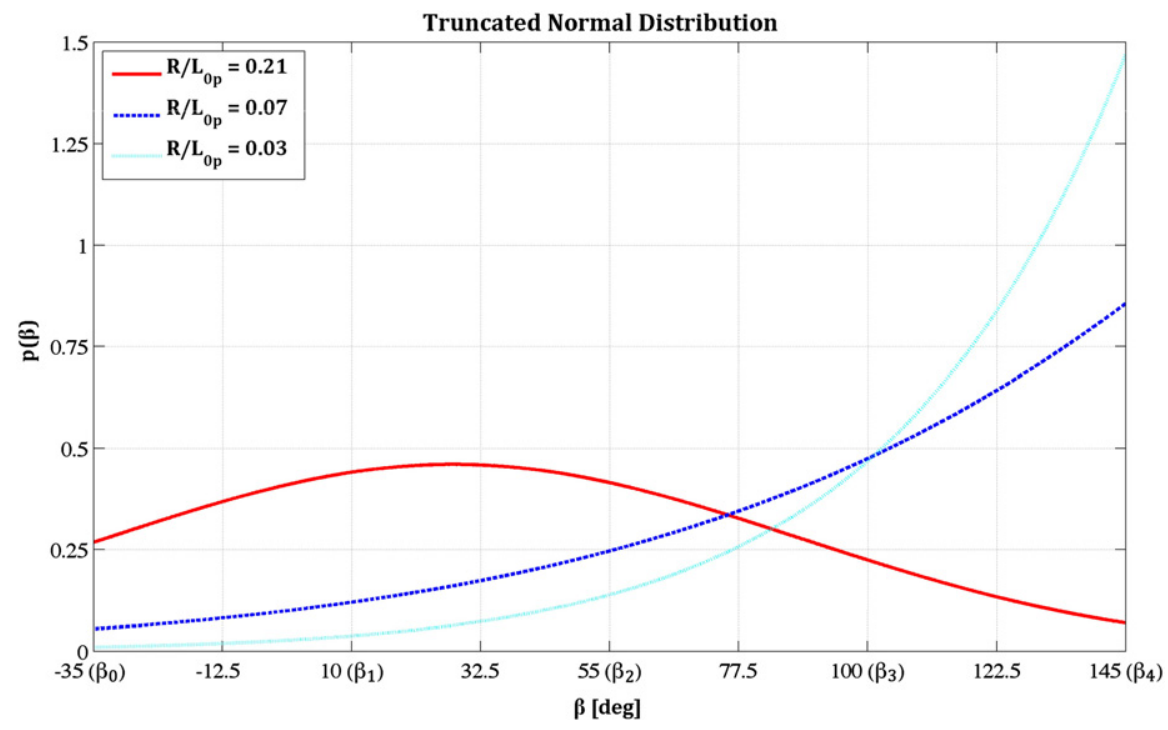

Fig. 6. Representation of $\mu(\beta)$, expressed by Eq. (3), for different values of the $R / L_{0 p}$ ratio. 


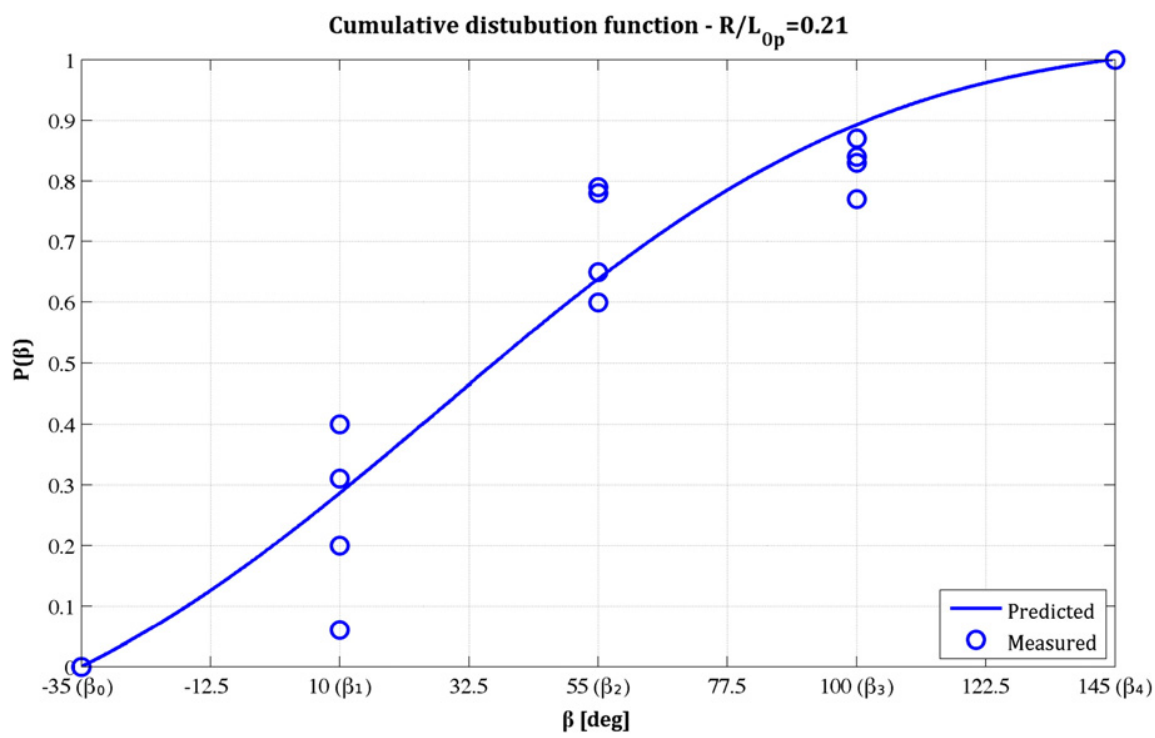

Fig. 7. Predicted and measured cumulative distribution values for $R / L_{0 p}=0.21$.

wave direction. In fact, as observed also by Maciñeira and Burcharth (2008), the wave period is among the most important parameters that influence damage distribution;

- under short wave periods, i.e. larger $R / L_{0 p}$ ratio in the figures, the damage is more uniform over the roundhead, and a slightly higher damage level appears in the frontal sectors. Under long wave periods, instead, the damage is almost totally concentrated in the last two sectors. In the results of the tests of Maciñeira and Burcharth (2008) a similar effect of wave period is observed;

- wave spreading $s$ and peak enhancement factor $\gamma$ do not seem to significantly influence damage pattern.

The adopted normal truncated distribution seems adequate to investigate the damage pattern.

It would be desirable that other investigations of the same kind were carried out to cover other relevant values of $R, R / L_{0 p}$ and slope angles. This would provide a solid experimental support to the analysis, and allow us to derive a general formula for the parameters of the damage pattern distribution (Eq. (4)).

\subsection{Damage progression}

The purpose of this section is to provide a stability formula to predict the development of global damage $D_{\%}$ over the roundhead armour layer, being $D_{\%} \in[0 ; 100]$ defined as:

$D_{\%}=\frac{N_{d}}{N_{t}} \cdot 100$

Where:

$N_{d} \quad$ is the number of displaced stone units within the roundhead; $N_{t} \quad$ is the total number of stone units within the active zone of the roundhead ( 670 stones).

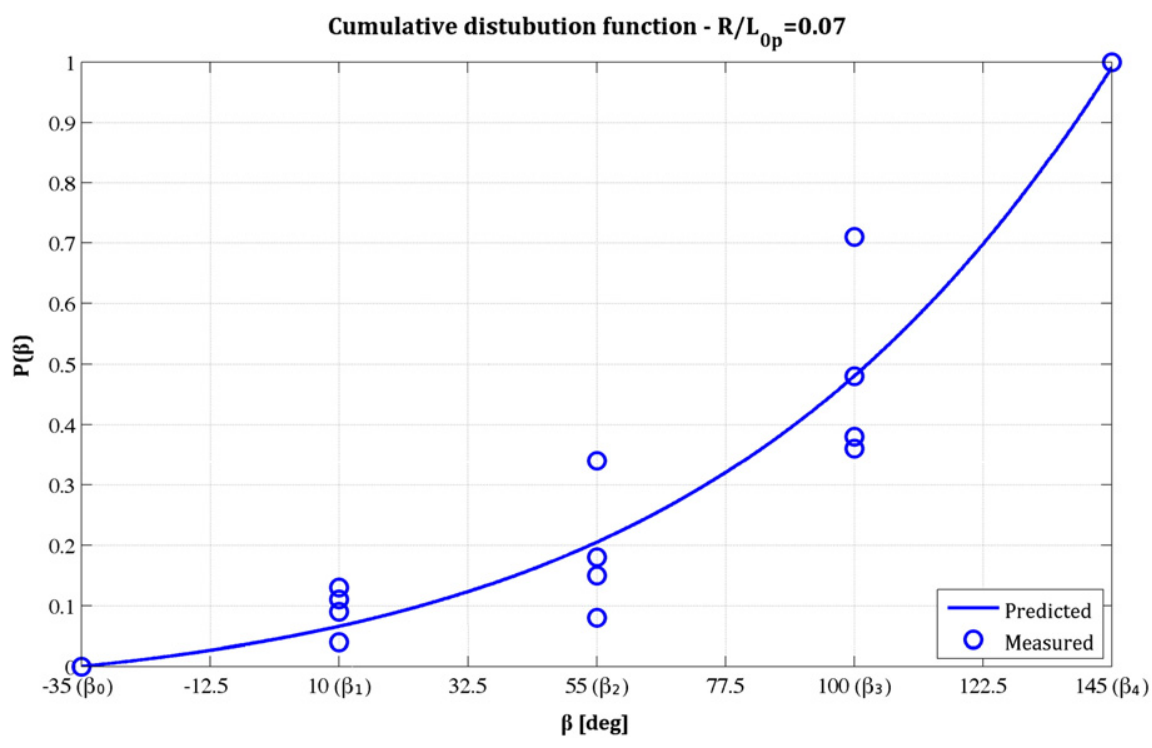

Fig. 8. Predicted and measured cumulative distribution values for $R / L_{0 p}=0.07$. 


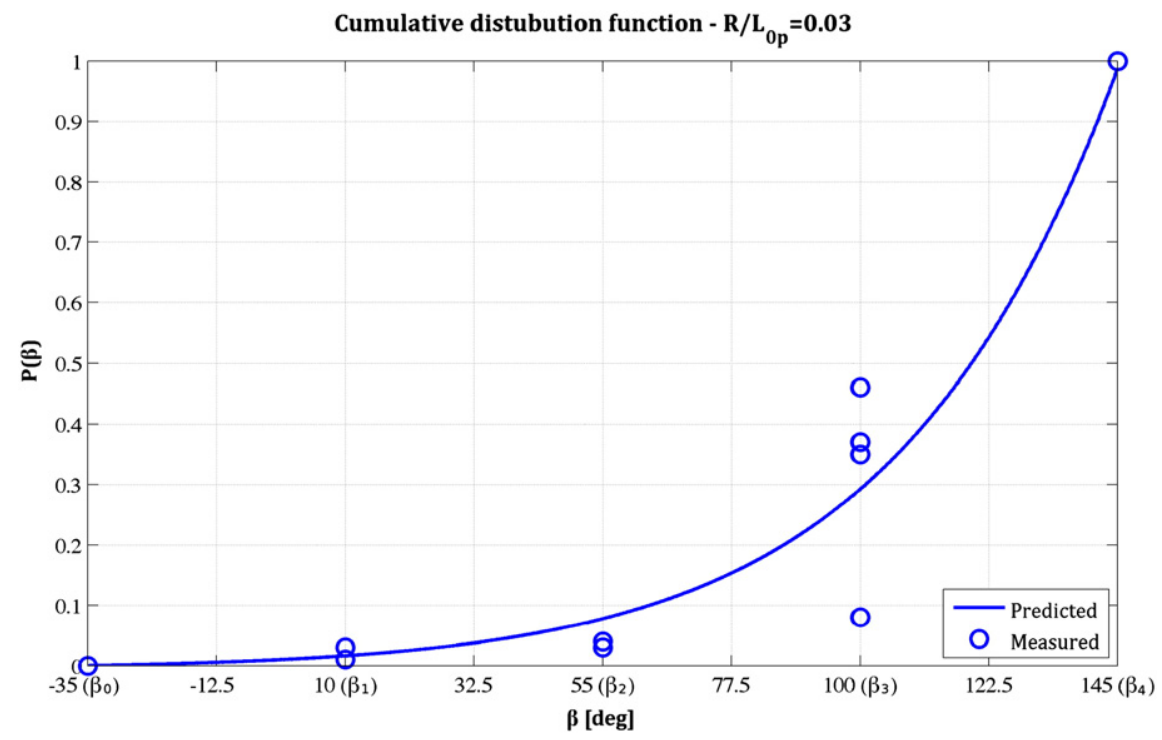

Fig. 9. Predicted and measured cumulative distribution values for $R / L_{0 p}=0.03$.

Fig. 10 shows the trend of the experimental results in the plane $N_{s}-D_{\%}$, marking with different symbols (and colours) for different $R / L_{0 p}$ values.

The experimental trends lead to the following main conclusions, based on Fig. (10):

- Initial damage $\left(D_{\%}=1 \div 2\right)$ seems to take place under the same stability number, regardless of the wave peak period. This confirms that initial damage is not influenced by wave steepness, as observed by Berenguer and Baonza (1999), Vidal et al. (1989, 1991) and Madrigal and Lozano (1992);

- Damage progression is much faster under long wave periods $\left(R / L_{0 p}=\right.$ 0.03). This is consistent with the result of Maciñeira and Burcharth (2007), who observed a larger residual stability under short waves than under long waves;

- Damage progression is not significantly influenced by peak enhancement factor $\gamma$ and directional spreading $s$ (i.e. dots with same $R / L_{0 p}$ have similar $D_{\%}$ );
- The failure condition is reached for a global damage level $D_{\%}$ in range 15-20, as was also observed by Berenguer and Baonza (1999), using cubes and BCRs.

In the following analysis the structure of the formula of Berenguer and Baonza (Eq. (1)) is adopted as model, since the variables involved in such expression are the same as considered in this study (i.e. stability number, damage level and wave steepness). The resulting stability formula is therefore validated for an armour slope $1: 1.5$ and a radius $R=16.35 D_{n 50}$. The coefficients of the formula are calibrated to fit the trend of experimental points $\left(N_{s}, D_{\%}\right)$, leading to the following expression:

$\hat{N}_{s}=0.94+0.74 \cdot D_{\%}^{0.42} \cdot S_{0 p}^{0.23}$

Figs. 11, 12 and 13 show the fitting of the proposed stability formula (Eq. (6)) to the experimental points, for different values of $R / L_{0 p}$.

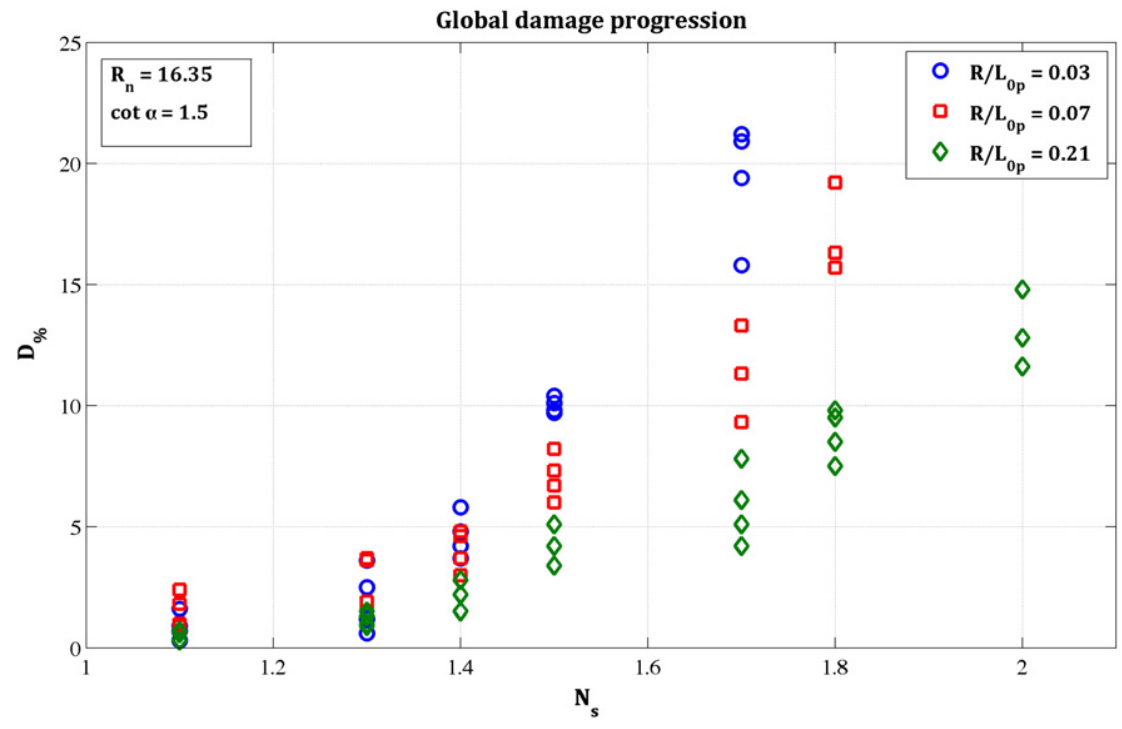

Fig. 10. Progression of global damage with increasing significant wave height. 


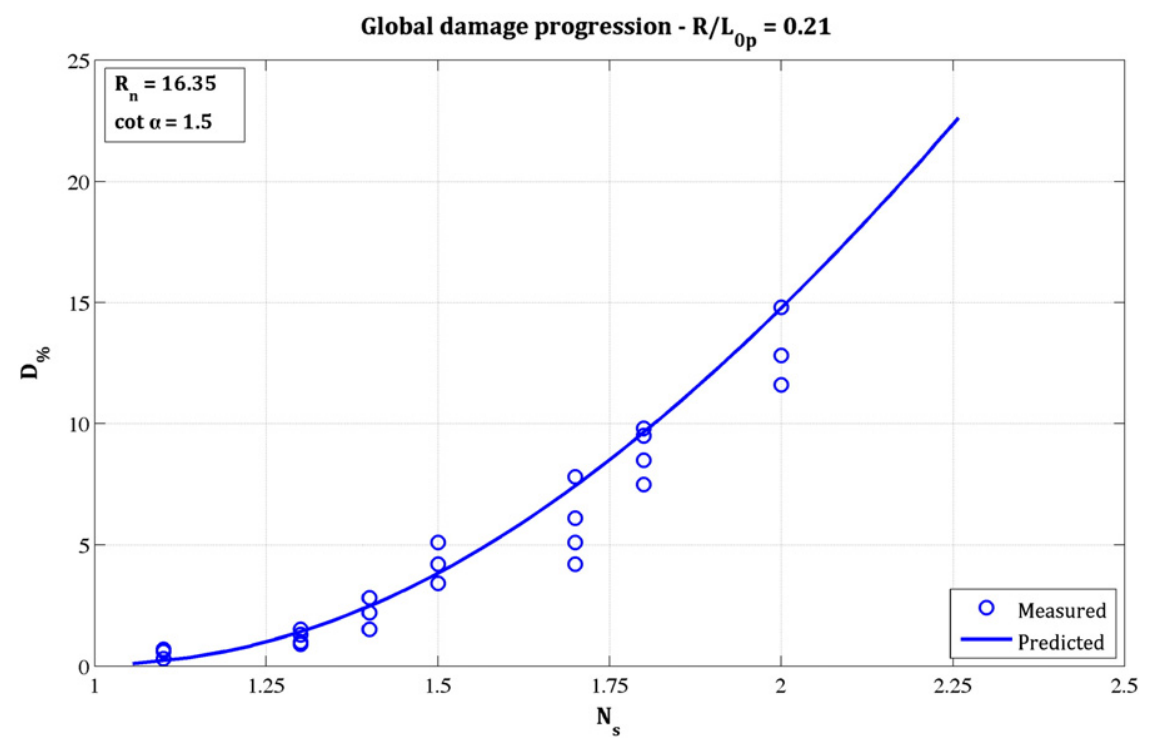

Fig. 11. Fitted global damage progression for short wave periods.

Fig. 14 shows the comparison between the measured values of $N_{s}$ and the ones computed according to Eq. (6). It can be observed that, even though a scattering effect is visible, the points are sensibly placed along the bisect.

The dotted line in Fig. 14 is a possible design (conservative) formula. This line is obtained by decreasing the computed values of $N_{s}$ by $2 \cdot \sigma_{e}$, being $\sigma_{e}$ the mean standard deviation of the error.

Eq. (7) gives the expression of the conservative stability formula related to the dotted line, validated for roundheads armoured with quarry stones, having $\cot \alpha=1.5$ and $R_{n}=16.35$ (Table 4).

$\hat{N}_{s}=0.83+0.74 \cdot D_{\%}^{0.42} \cdot S_{0 p}^{0.23}$.

The failure condition in the roundhead generally occurs when the filter layer in the critical sector starts to be visible and thus the damage value in the critical sector $D_{\%, \text { crit }}$ may be a suitable parameter to characterize the failure condition for the roundhead. Maciñeira and Burcharth (2007) provided different damage levels for practical design and proposed to identify the failure condition of a cube armoured roundhead with a value of $D_{\%, \text { crit }}$ between 15 and 20, depending on the radius. In the present tests, it has been observed that for $D_{\% \text {,crit }}$ between 30 and 35 (approximately 50 of the 167 units in the active zone of the critical sector) the filter layer is generally exposed for an area wider than $D_{n 50}$.

The global damage may be related to the damage in the critical sector using Eq. (8), where the fraction of displaced units in the critical sector $P_{\text {crit }}$ is provided by the damage pattern analysis. For example, assuming a value of $P_{\text {crit }}=0.65$ is predicted using Eq. (4) and using $D_{\%, \text { crit }}=20$ as design value, the total number of displaced units in failure conditions is $167 \cdot 0.20 / 0.65=50$. The global damage is then obtained by dividing 50 for $4 * 167$, that is the total number of units in the active zone of the roundhead. In summary:

$D_{\%}=\frac{D_{\%, \text { crit }}}{4 P_{\text {crit }}}$.

By using $D_{\%, \text { crit }}$ as a design parameter, the proper size for roundhead units may be derived by replacing Eq. (8) in the stability formula (Eq. (7)).

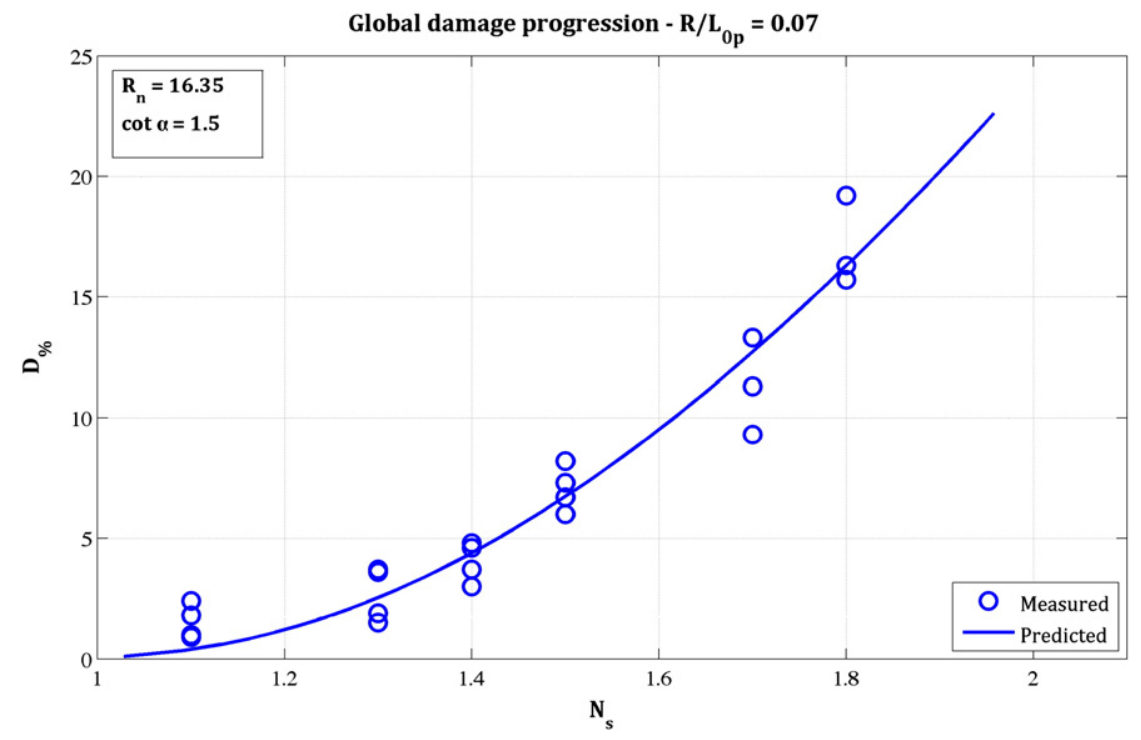

Fig. 12. Fitted global damage progression for intermediate wave periods. 


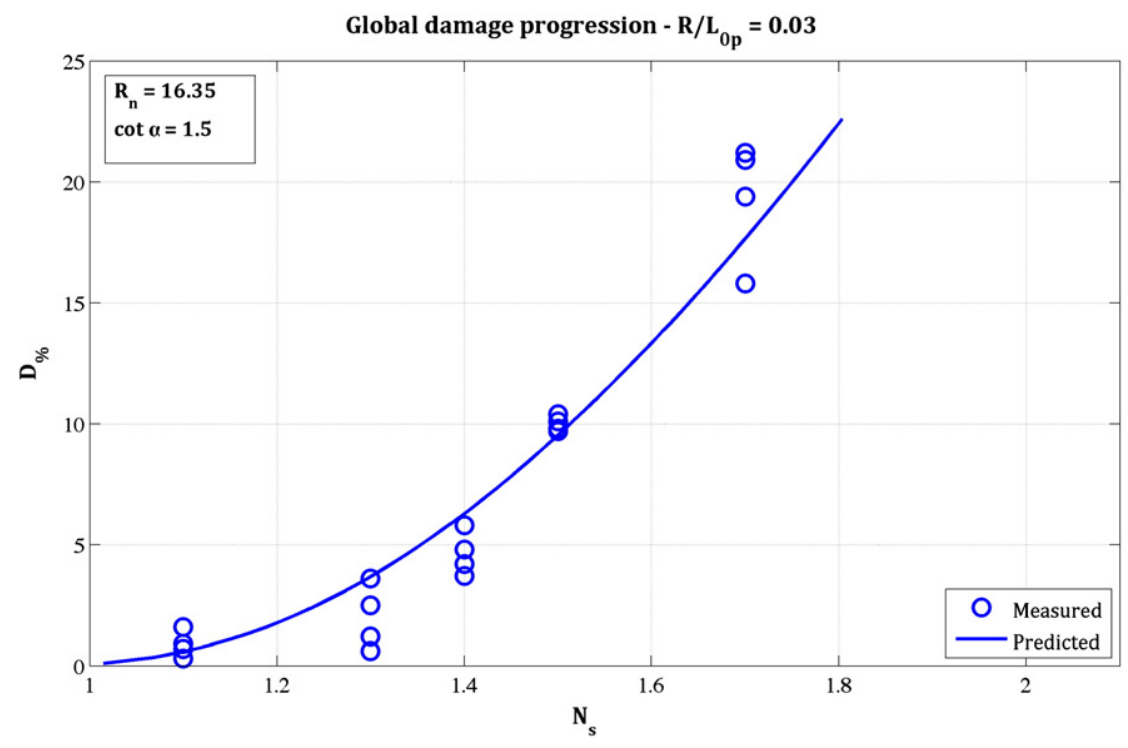

Fig. 13. Fitted global damage progression for long wave periods.

\subsection{Damage development in the critical sector}

In this section the proposed stability formula (Eq. (6)) is be combined with the results obtained by the damage pattern analysis to provide a reliable predictive model for the damage development in the critical sector. The results will be compared with the ones obtained by applying the formula of Maciñeira and Burcharth (2007).

The advantage of the new approach is that it may be adopted both when the critical sector is the one between $\left[90^{\circ}-135^{\circ}\right]$ degrees from wave main direction, as Maciñeira and Burcharth (2007) observed, but also when the critical sector is shifted to the frontal sectors under short waves attack. In this last case, as it will be shown, the new approach is able to provide more reliable results.

The analysis is carried out considering the three tested values of $R / L_{0 p}$ $(0.03,0.07$ and 0.21$)$. For each of them, the probability density function

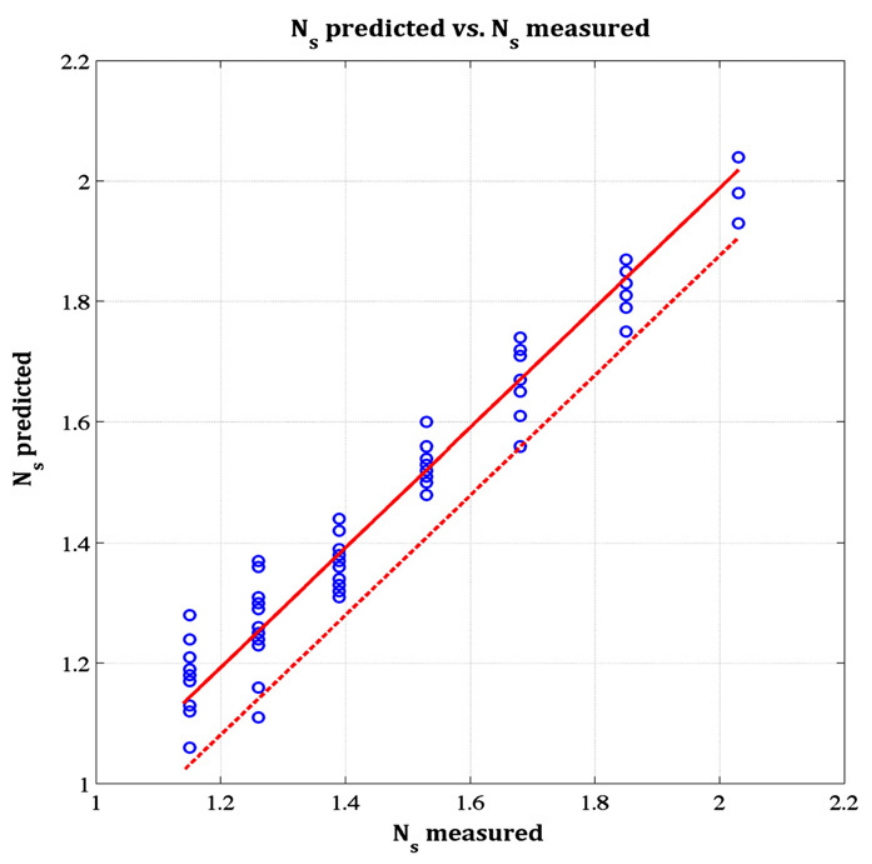

Fig. 14. Comparison between measured and computed $N_{s}$.
(Eq. (4)) is applied to assess which one of the four sectors is the critical one. In order to do this, Eq. (4) is integrated numerically between the delimiting angles of each sector (Fig. 4), considering the fitted values of $\mu$ and $\sigma$ shown in Fig. 5 . The critical sectors given in Table 5 have been identified.

Replacing Eq. (8) in Eq. (6) the following relation between $N_{s}, S_{0 p}$ and $D_{\%, \text { crit }}$ is obtained:

$\hat{N}_{s}=0.94+0.41 \cdot\left(\frac{D_{\%, c s}}{P_{\text {crit }}}\right)^{0.42} \cdot S_{0 p}^{0.23}$.

Figs. 15 and 16 show the comparison between the formula (Eq. (2)) of Maciñeira and Burcharth (2007) and the new stability formula (Eq. (9)). One may observe that, in the cases in which sector 4 is actually the critical one, both formulae show good predicting skills. However, in case sector 2 is the critical one, the new formula (Eq. (9)) is more reliable than the formula of Maciñeira and Burcharth (2007) (Eq. (2)).

Table 4

Ranges used to validate the stability formula.

\begin{tabular}{ll}
\hline Parameter & Value \\
\hline Stability number $N_{s}$ & $1.1-2.0$ \\
Global damage $D_{\%}$ & $0-20$ \\
Wave steepness $S_{0 p}$ & $0.004-0.041$ \\
Spreading coefficient $s$ & $5-50$ \\
Peak enhancement factor $\gamma$ & $3.3-10.0$ \\
Armour slope cot $\alpha$ & 1.5 \\
Dimensionless radius $R_{n}$ & 16.35 \\
Dimensionless density $\Delta$ & 1.57 \\
Number of waves per test & 1000 \\
Wave mean direction & $35^{\circ}$ \\
\hline
\end{tabular}

Table 5

Critical sector corresponding to each value of $R / L_{0 p}$ and corresponding damage probability.

\begin{tabular}{lll}
\hline$R / L_{0 p}$ & Critical sector & $P_{\text {crit }}$ \\
\hline 0.03 & Sector 4 & 0.71 \\
0.07 & Sector 4 & 0.51 \\
0.21 & Sector 2 & 0.36 \\
\hline
\end{tabular}


Damage progression in the critical sector 4

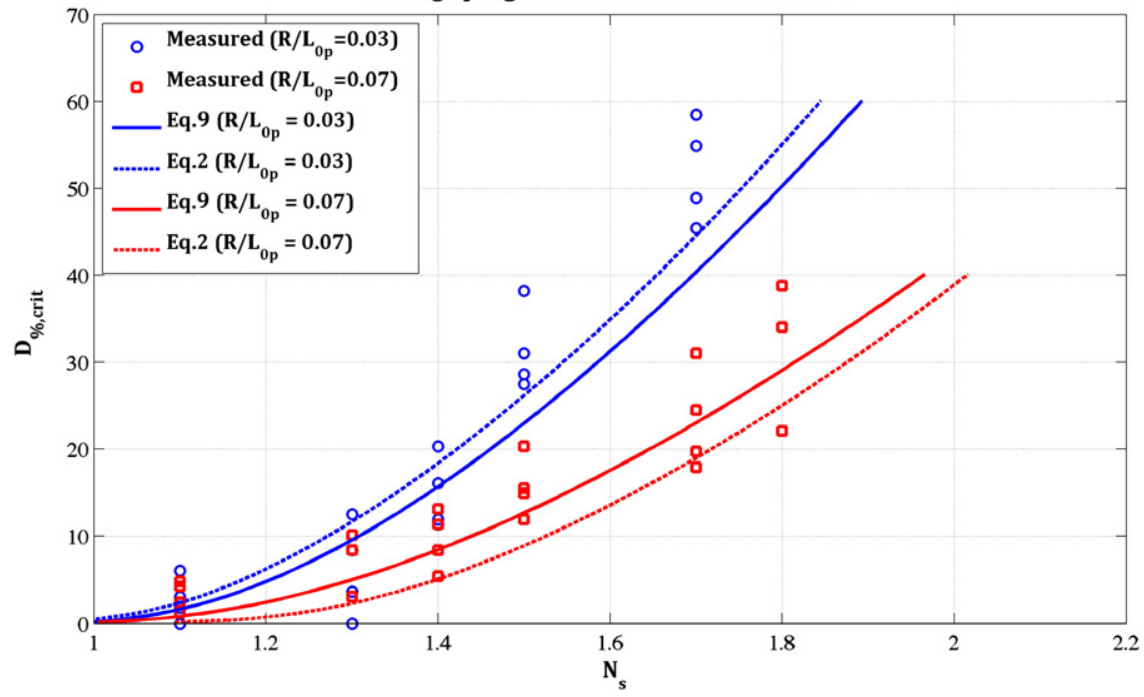

Fig. 15. Fitting quality of Eqs. (2) and (9) in case sector 4 is the critical one.

\section{Guidelines for applications to double peaked spectra}

Some experimental tests have been performed to provide a better insight on the stability formula application to incident sea states having double peaked spectra.

The aforementioned spectra are characterized by energy concentrations around two peak frequencies, a higher one corresponding to the wind waves and a lower one corresponding to the swell waves. The peak enhancement factor, the spread coefficient and the wave mean direction (from the normal to the trunk) have been set equal to the values reported in Table 6 .

The quantitative tools developed in the damage pattern and damage progression analysis are tested for double peaked spectra considering the following expressions for $H_{s, t o t}, T_{p, e q}$ and $R / L_{0 p, e q}$ :

$$
\begin{aligned}
& H_{s, \text { tot }}=\sqrt{H_{s, \text { swell }}^{2}+H_{s, \text { wind }}^{2}} \\
& T_{p, \text { eq }}=\frac{T_{p, \text { swell }} H_{s, \text { swell }}^{2}+T_{p, \text { wind }} H_{s, \text { wind }}^{2}}{H_{s, \text { swell }}^{2}+H_{s, \text { wind }}^{2}}
\end{aligned}
$$

$\frac{R}{L_{0 p, e q}}=\frac{2 \pi R}{g T_{p, e q}^{2}}$

The experimental conditions and the values of $H_{s, t o t}, T_{p, e q}$ and $R / L_{0 p, e q}$ associated to every test are shown in Table 7.

The formulae for damage pattern and progression are applied, using the variables defined in Eqs. (10)-(12), to predict the results of these tests. Fig. 17 presents the damage pattern results compared to Eq. (4) in terms of cumulative distributions.

It may be observed that the measured points, having a value of $R / L_{0 p, e q} \approx 0.05$, lay between the analytical curves for $R / L_{0 p}=0.07$ and $R / L_{0 p}=0.03$. These results suggest that $R / L_{0 p, e q}$ is suitable to replace $R / L_{0 p}$ for damage pattern analysis under double peaked spectra.

In Fig. 18 the measured values of stability number are compared with the stability formula Eq. (6).

Computed and measured results show a good correspondence, as the relative error is lower than $10 \%$ for every $N_{s}$ value. It can be observed however that the measured values are slightly underestimated for $N_{\mathrm{s}}<1.5$ and slightly overestimated for $N_{\mathrm{s}}>1.5$.

Damage progression in the critical sector 2

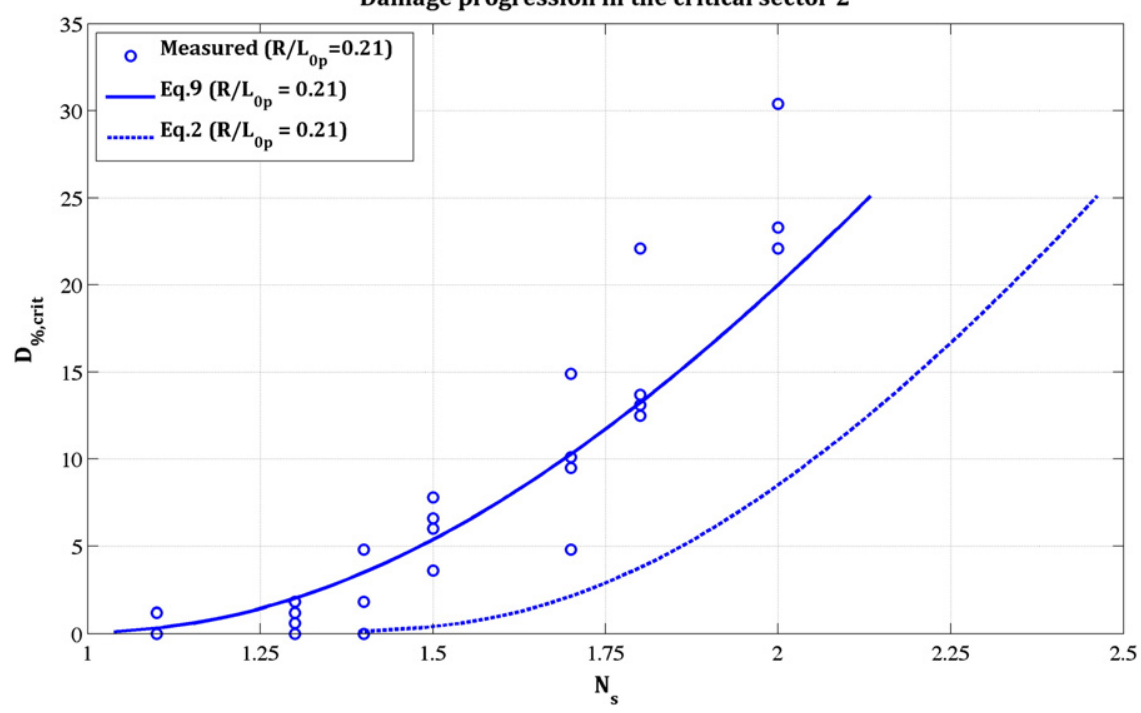

Fig. 16. Fitting quality of Eqs. (2) and (9) in case sector 2 is the critical one. 
Table 6

Spectral parameters of the tested double peaked spectra.

\begin{tabular}{lllll}
\hline & $\begin{array}{l}\text { Spectrum } \\
\text { type }\end{array}$ & $\begin{array}{l}\text { Peak enhancement } \\
\text { factor } \gamma\end{array}$ & $\begin{array}{l}\text { Wave mean } \\
\text { direction }\end{array}$ & $\begin{array}{l}\text { Spread } \\
\text { coefficient s }\end{array}$ \\
\hline Wind waves & JONSWAP & 3.3 & $15^{\circ}$ & 10 \\
Swell waves & JONSWAP & 10 & $35^{\circ}$ & 50 \\
\hline
\end{tabular}

Table 7

Wave parameters for double peaked spectra.

\begin{tabular}{llllllll}
\hline Test & $\begin{array}{l}T_{p, \text { swell }} \\
{[\mathrm{s}]}\end{array}$ & $\begin{array}{l}T_{p, \text { wind }} \\
{[\mathrm{s}]}\end{array}$ & $\begin{array}{l}T_{p \text { eq }} \\
{[\mathrm{s}]}\end{array}$ & $\begin{array}{l}H_{s, \text { swell }} \\
{[\mathrm{cm}]}\end{array}$ & $\begin{array}{l}H_{s, \text { wind }} \\
{[\mathrm{cm}]}\end{array}$ & $\begin{array}{l}H_{s, \text { tot }} \\
{[\mathrm{cm}]}\end{array}$ & $R / L_{0 p, e q}$ \\
\hline Test 1 & 3.0 & 1.1 & 2.6 & 6.0 & 3.4 & 6.9 & 0.06 \\
Test 2 & 3.0 & 1.4 & 2.6 & 6.3 & 3.7 & 7.3 & 0.06 \\
Test 3 & 3.4 & 1.4 & 2.7 & 6.3 & 4.3 & 7.6 & 0.05 \\
Test 4 & 3.2 & 1.4 & 2.7 & 6.9 & 4.0 & 7.9 & 0.05 \\
Test 5 & 3.4 & 1.4 & 2.7 & 7.1 & 4.9 & 8.6 & 0.05 \\
Test 6 & 3.2 & 1.4 & 2.7 & 7.4 & 4.6 & 8.7 & 0.05 \\
Test 7 & 3.4 & 1.4 & 2.7 & 7.4 & 5.1 & 9.0 & 0.05 \\
Test 8 & 3.0 & 1.4 & 2.7 & 8.0 & 4.3 & 9.1 & 0.05 \\
Test 9 & 3.4 & 1.4 & 2.7 & 8.0 & 5.4 & 9.7 & 0.05 \\
Test 10 & 3.4 & 1.4 & 2.8 & 8.3 & 5.4 & 9.9 & 0.05 \\
\hline
\end{tabular}

The conclusion is that, under double peaked spectra, Eqs. (10)-(12) are useful to characterize both the damage pattern and the stability.

\section{Conclusions}

The aim of this study was to investigate the damage pattern and progression on a rock armoured rubble-mound breakwater roundhead under multidirectional waves. The experimental analysis was performed on a small scale physical model, installed in the shallow water basin of Aalborg University, equipped with segmented wave generation system able to generate multi-directional waves of given spectral characteristics.

The results in terms of damage pattern demonstrated that the wave peak period has a fundamental influence in defining the most damaged roundhead sector. Indeed, under short wave periods the frontal sectors were the most subjected to stone displacements and, under increasing wave periods, the rear sectors were instead the most damaged ones. A truncated normal distribution is proposed for the prediction of the damage pattern over the roundhead armour layer. The 2 parameters of the truncated distribution seem to be mainly dependent on $T_{p}$, and they were associated to the non-dimensional ratio $R / L_{0 p}, R$ being the

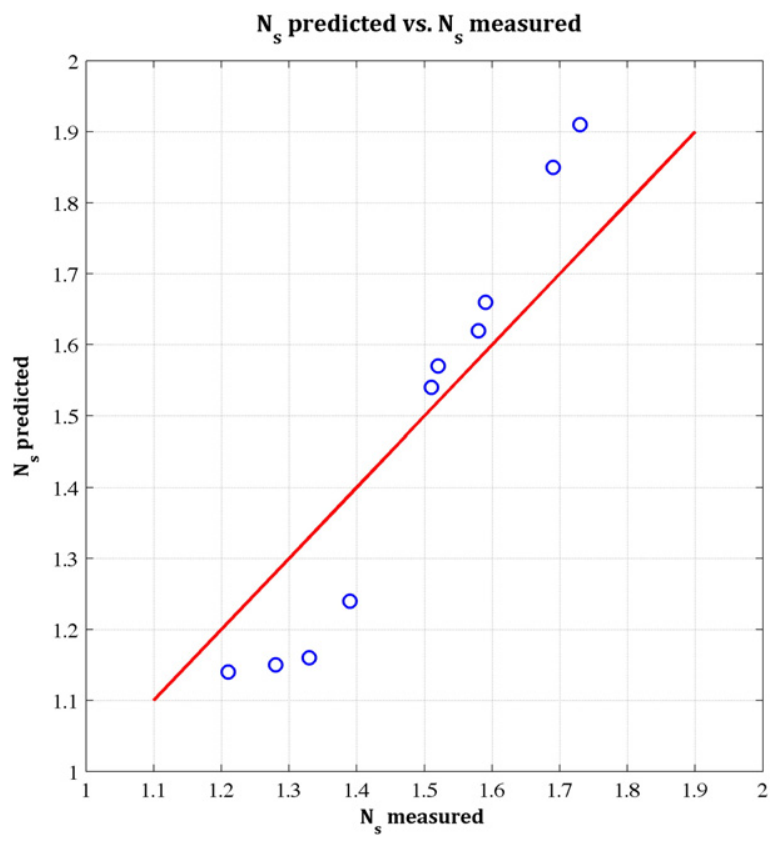

Fig. 18. Comparison between measured and computed $N_{s}$ for double peaked spectra.

roundhead radius at SWL (fixed in the experiments) and $L_{0 p}$ the deep water wave length (dependent on $T_{p}$ ).

As far as the damage progression is concerned, it was verified that the wave period does not influence the occurrence of initial damage. However, once the first stone displacements take place, the damage progression is much faster under long waves than under short ones. Moreover, the directional spreading and the spectral width were found to have little influence on damage pattern and global damage progression. The failure condition, occurring when the filter layer is exposed to wave attack, was always observed when the damage level was between 15 and $20 \%$. A stability formula giving the stability number $N_{s}$ as a function of the global damage within the roundhead active zone $D_{\%}$ and the wave steepness $S_{0 p}$, was finally derived for the tested geometry of the roundhead. It was shown that, if coupled to the results of the damage pattern analysis, this formula also provides good prediction of the damage development in the critical sector. This prediction is similar to the one given by other formulae in the literature when the critical

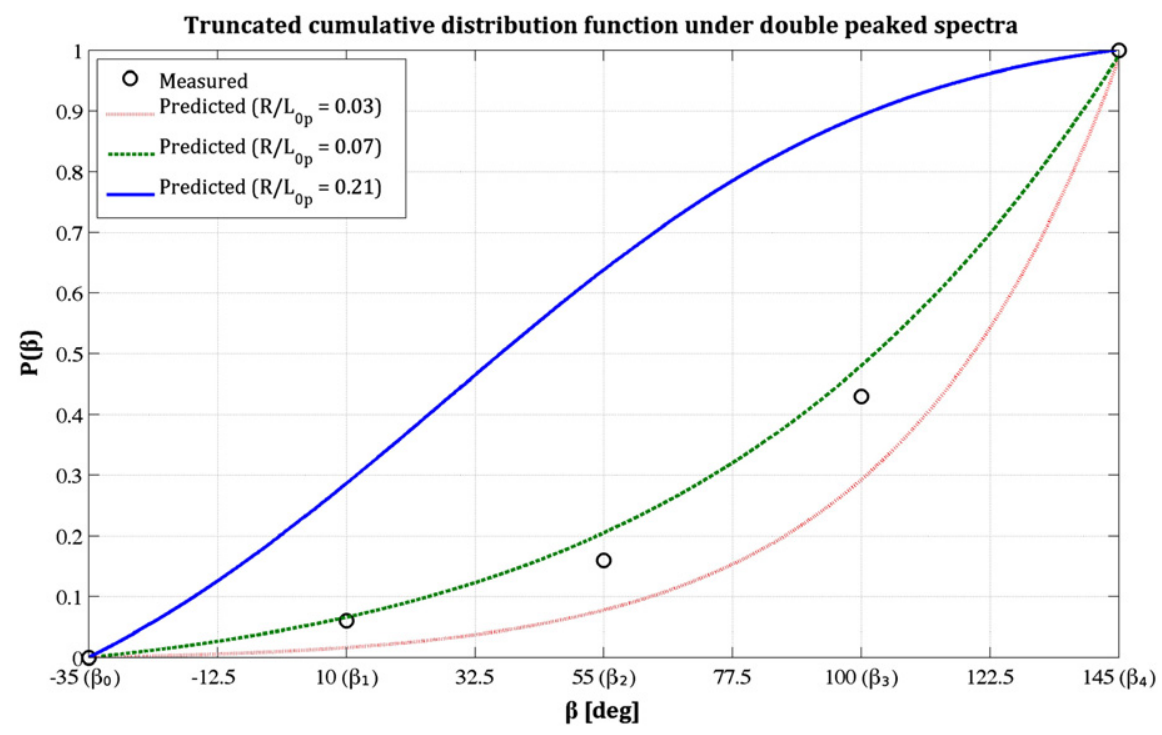

Fig. 17. Comparison between measured and predicted damage pattern for double peaked spectra. 
sector is between $100^{\circ}$ and $145^{\circ}$ from wave mean direction, but is more reliable when the critical sector shifts to the frontal side of the roundhead. It is believed that this last formula could for the tested geometry provide a valid (and slightly conservative) approach to design the proper dimension for the stones of the roundhead armour layer.

Some additional tests involving double peaked spectra signifying swell and wind seas with $20^{\circ}$ deviations in mean direction could provide guidelines for the application of the previous tools to sea state conditions given by the superposition of wind waves and swell waves. The results pointed out that the proper stone dimension may be evaluated by considering the total significant wave height $H_{s, t o t}$ and the equivalent peak period $T_{p, e q}$ in the proposed stability formula. Similarly, the normal truncated distribution, derived for the damage pattern under waves characterized by a single peak frequency, fitted the observations in the double peaked case using $T_{p, e q}$ in place of $T_{p}$, i.e. considering $R / L_{0 p} \approx R / L_{0 p, e q}$.

\section{References}

Berenguer, J.M., Baonza, A., 1999. Experimental research on hollowed cubes for breakwater protection. Coast. Struct. 1999, 255-261.

Burcharth, H.F., Hughes, S.A., 2002. Coastal Engineering Manual, Part VI, Fundamentals of Design, Chapter V-1, Engineer Manual 1110-2-1100. U.S. Army Corps of Engineers, Washington, DC.

Burcharth, H.F., Thompson, A.C., 1983. Stability of armour units in oscillatory flow. Coast. Struct. 1983, 71-82.

Burcharth, H.F., Haagensen, R., Maciñeira, A.E., 2003. Stability of roundheads armoured with cubes. Coast. Struct. 2003, 67-77.

Carver, R.D., Heimbaugh, M.S., 1989. Stability of stone and dolos armored rubble-mound breakwater heads subjected to breaking and nonbreaking waves with no overtopping. U.S. Army Engineer Waterways Experiment Station, Technical Report CERC-89-4.

Comola, F., 2012. Analysis of Damage Pattern and Progression on a Breakwater Roundhead Under Multidirectional Waves. (Master Thesis) Università di Padova (http:// www.image.unipd.it/p.ruol/publications.html).

Dai, Y.B., Kamel, A.M., 1969. Scale effects tests for rubble-mound breakwaters. U.S. Army Engineer Waterways Experiment Station, Research Report H-69-2.
De Rouck, J., Geeraerts, J., Troch, P., Kortenhaus, A., Pullen, T., Franco, L., 2005. New results on scale effects for wave overtopping at coastal structures. Coastlines Structures Breakwaters, pp. 29-43.

Hashimoto, N., 1988. Directional spectrum estimation from a Bayesian approach. Proc. 21th ICCE, Malaga, Spain.

Jensen, J., 1984. A Monograph on Rubble Mound Breakwaters. Danish Hydraulic Institute, Hørsholm.

Johnson, N.L., Kotz, S., Balakrishnan, N., 1994. Continuous Univariate Distributions, vol. 1. Wiley (Section 10.1).

Losada, M.A., Dalrymple, R.A., Vidal, C., 1990. Water waves in the vicinity of breakwaters. J. Coast. Res. I, 119-138.

Lykke Andersen, T., Burcharth, H.F., Gironella, X., 2010. Comparison of new large and small scale overtopping tests for rubble-mound breakwaters. Coastal Engineering 58 (4), 351-373.

Maciñeira, A.E., 2004. Determinacion de una formula para el calculo de la esatabilidad del morro de un dique en talud. Analysis de los distintos facotores que intervienen. (Ph.D. Thesis) Unversidade da Coruña.

Maciñeira, E.A., Burcharth, H.F., 2007. New formula for stability of cube armoured roundheads. Coast. Struct. I, 31-40.

Maciñeira, E., Burcharth, H.F., 2008. Spatial damage distribution over cube armoured roundheads. Proceedings of the 31st International Conference on Coastal Engineering, Hamburg, Germany, pp. 3449-3460.

Madrigal, G., Lozano, J., 1992. Stability of accropode and comparison with parallepipedic block. Civ. Eng. Oceans V, 704-717.

Martinelli, L., Zanuttigh, B., Lamberti, A., 2006. Hydrodynamic and morphodynamic response of isolated and multiple low crested structures: experiments and simulations. Coastal Engineering 53, 363-379.

Matsumi, Y., Kimura, A., Ohno, K., 1996. Velocity field measurements over breakwater heads under 3D waves. Coastal Engineering 1996, 1777-1788.

Matsumi, Y., Kimura, A., Ohno, K., 1998. Wave kinematics on breakwater heads and stability of armour layers under multidirectional waves. Coastal Engineering 1998, 1907-1919.

Matsumi, Y., Kimura, A., Ohno, K., 2000. Stability of armour units on breakwater heads under multidirectional waves. Coastal Engineering 2000, 1946-1958.

Matsumi, Y., Mansard, E.P.D., Rutledge, J., 1994. Influence of wave directionality on stability of breakwaters heads. Coast. Eng. 1994, 1397-1411.

United States Army Corps of Engineers, 1984. Shore Protection Manual. Dept. of the Army, Waterways Experiment Station, Vicksburg.

Vidal, C., Losada, M.A., Medina, R., 1991. Stability of mound breakwater's head and trunk. J. Waterways Port Coast. Ocean Eng. 117 (6), 570-587.

Vidal, C., Losada, M.A., Medina, R., 1989. Estabilidad del Morro de los Diques en Talud. Influencia de sua Geometria. Revista de Obras Publicas. 887-907. 